\title{
Investigation of Line-Commutated Three-Phase Converters Under Voltage Unbalance
}

\author{
Manuel Weiland ${ }^{1}$, Gerhard Herold ${ }^{1}$ \\ ${ }^{1}$ Institute of Electrical Power Systems \\ University of Erlangen-Nuremberg \\ Cauerstr. 4 - Haus 1, 91058 Erlangen (Germany) \\ Phone/Fax number: +49 (9131) 85295 27/41, e-mail: weiland@eev.eei.uni-erlangen.de
}

\begin{abstract}
Power converters operated in unsymmetrical three-phase electrical systems will generally work asymmetrically. This introduces disadvantages for the operation of the electrical power system, like non-characteristic harmonics. In the case of controllable power converters, such as thyristor converters, it is possible to operate the converter with asymmetrical firing angles. This offers the opportunity to react on the system's unbalance optimizing the asymmetrical operation of the converter to lower the disadvantages.

In this paper, a method is presented to calculate the behaviour of electrical equipment based on line-commutated current converters. Thereby, the operation of the essentially non-linear system is described as sectional continuous linear problem. For its solution an approach with differential equations in the range of space-phasors is used. It is shown to be possible to optimize the unsymmetrical operation with respect to certain quality criteria by using unsymmetrical firing angles.
\end{abstract}

\section{Keywords}

Power converter, voltage unbalance, converter control, distortion, optimization

\section{Introduction}

Unsymmetrical loads, transmission lines and faults in three-phase electrical power systems can cause the mains voltage at the point of coupling to be unbalanced. Line-commutated power converters and similar electrical power equipment, like FACTS and HVDC converters operated with this unbalanced voltage, will work asymmetrically. As this asymmetrical operation causes some drawbacks, such as the appearance of non-characteristic harmonics and higher distortion levels, it is worthwhile to calculate an optimized operation mode of the asymmetrical current converter system. As the system's parameters, the grade of unbalance and the desired DC-power are given and not changeable, the only possibility for an optimization is a modification of the firing angles.

The aim is now to calculate optimal firing angles for a given system with a given grade of unbalance. Due to the unbalance, the optimal firing angels will be asymmetrical. This optimization is calculated here with differential equations and space-phasors. Thereby, no requirements to the AC-line and DC impedances have to be complied with, except of linearity. In particular, this means that the
AC-line impedance does not have to be negligible and may have a resistive part. The DC-network may have a non-infinite reactance, which corresponds to a ripple-afflicted DC-current. Capacitive elements can be included both on the $\mathrm{AC}$ and $\mathrm{DC}$ side of the converter, which introduces the possibility to take filter into account. With this asymmetric control strategy, it is possible to optimize the converter's operation with respect to various quality criteria, such as distortion of the DC-current, distortion of the AC-currents or the elimination of harmonics.

\section{Formulation of the Problem}

Though the drafted approach is applicable for any arbitrary complex electrical power system and any $n$-pulse line-commutated current converter, it will be shown by means of a simple sample system consisting of a six-pulse thyristor bridge and unbranched AC- and DC-networks of ohmic-inductive type according to fig. 1. An unbalance is introduced through an unbalanced sinusoidal three-phase mains voltage $u_{p R, S, T}$

$$
\begin{aligned}
& u_{p R}(\tau)=\hat{U}_{p R} \cos \left(\omega \tau+\varphi_{p R}\right), \\
& u_{p S}(\tau)=\hat{U}_{p S} \cos \left(\omega \tau-2 \pi / 3+\varphi_{p S}\right), \\
& u_{p T}(\tau)=\hat{U}_{p T} \cos \left(\omega \tau-4 \pi / 3+\varphi_{p T}\right),
\end{aligned}
$$

wherein in general is $\hat{U}_{p R} \neq \hat{U}_{p S} \neq \hat{U}_{p T}$ $\varphi_{p R} \neq \varphi_{p S} \neq \varphi_{p T}$.

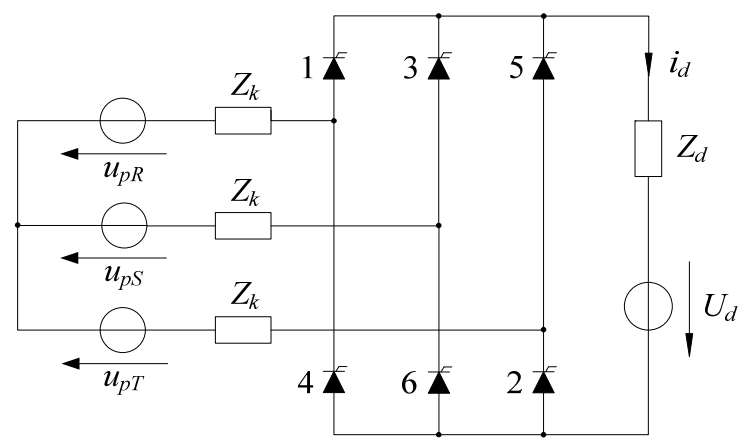

Fig. 1: Schematic diagram of the analyzed system 


\section{Description with Space Phasors}

The problem is investigated with space phasors, which are defined for any time-dependent three-phase system $v_{R, S, T}(\omega t)$

$$
\underline{v}(\omega t)=\frac{2}{3}\left(v_{R}(\omega t)+\underline{a} v_{S}(\omega t)+\underline{a}^{2} v_{T}(\omega t)\right)
$$

with $\underline{a}=\mathrm{e}^{\mathrm{j} 2 \pi / 3}$. To achieve a manageable description of the transient parts of the later stated differential equations, the calculation start angle $\omega t=0$ refers to the beginning of the conduction of thyristor 3 . The phase of the mains voltage at that start angle is considered through a phase angle $\gamma$ according to

$$
\gamma=\omega(\tau-t) .
$$

With this, the space-phasor of the unbalanced sinusoidal mains voltage in eq. (1) to (3) is of two pulse type

$$
\underline{u}_{p}(\omega t) \mathrm{e}^{\mathrm{j} \varphi_{a, b}}=\left(\underline{\hat{U}}_{+1} \mathrm{e}^{\mathrm{j}(\omega t+\gamma)}+\underline{\hat{U}}_{-1} \mathrm{e}^{-\mathrm{j}(\omega t+\gamma)}\right) \mathrm{e}^{\mathrm{j} \varphi_{a, b}},
$$

which causes the six-pulse current converter to work in an asymmetrical two-pulse operation mode. During one period of the two-pulse operation there are six conducting states of the current converter. Fig. 2 shows the active thyristors during these states. Herein, $\mathrm{T}(1,2,3)$ stands for the active thyristors 1,2 and 3 and $\beta_{1}$ is the angle thyristor 1 stops conducting, which corresponds to the end of commutation.

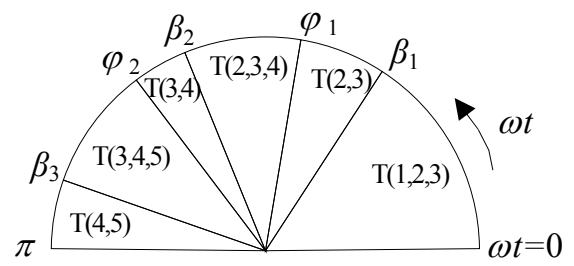

Fig. 2: Active thyristors during one two-pulse period

The firing angels $\varphi_{1}$ and $\varphi_{2}$ and the phase angle $\gamma$ are degrees of freedom, similar to the delay angle in a normal symmetrical six-pulse operation. These degrees of freedom will be used to control the quality of the asymmetric operation. In asymmetrical operation, the six states will generally differ in their duration.

As the investigation is carried out in the range of space-phasors, the system has to be transformed into its space-phasor description for every conduction state. This is drafted here for the conducting state $\mathrm{T}(1,2,3)$, which is shown in fig. 3.

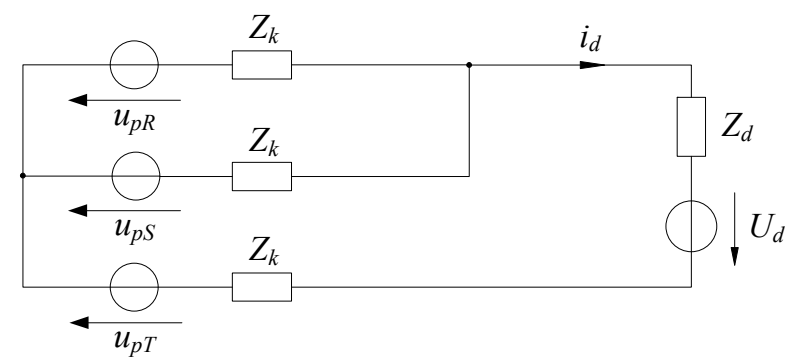

Fig. 3: System during conducting state $\mathrm{T}(1,2,3)$
With eq. (4) the current space-phasor of the network shown in fig. 3 is

$$
\underline{i}_{\mathrm{T}(1,2,3)}(\omega t)=\frac{2}{3}(1-\underline{a}) i_{k}(\omega t)-\underline{a}^{2} i_{d}(\omega t) .
$$

Herein is

$$
i_{k}(\omega t)=\frac{\sqrt{3}}{2} \operatorname{Im}\{\underline{a} \underline{i}(\omega t)\}=\frac{1}{2}\left(i_{R}(\omega t)-i_{S}(\omega t)\right)(8)
$$

the commutation current, that only exists during the states with three conducting thyristors and is defined differently for each of these three states. The corresponding space-phasor networks of the analyzed system for the conducting state $\mathrm{T}(1,2,3)$ are shown in fig. 4 .

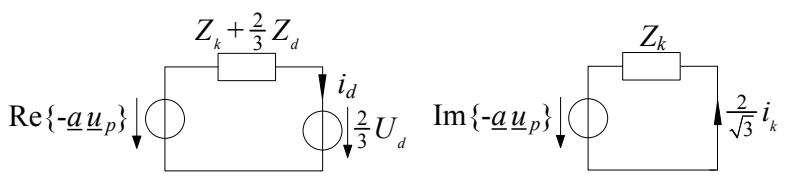

Fig. 4: Space-phasor networks for state $\mathrm{T}(1,2,3)$

The space-phasor networks for the other five states are obtained similarly. Thereby, the conducing states with two active thyristors contain only one state variable.

\section{Calculation with Differential Equations}

As the state variables of the investigated system are inductor currents only, the current space-phasor includes all state variables and has to be continuous at every change of the conducting state. At the time $\beta_{1}$ this is for example

$$
\underline{i}_{\mathrm{T}(2,3)}\left(\omega t=\beta_{1}+0\right)=\underline{i}_{\mathrm{T}(1,2,3)}\left(\omega t=\beta_{1}-0\right) .
$$

For $\varphi_{1}, \beta_{2}, \varphi_{2}, \beta_{3}$ and $\gamma$ analogue equations can be stated. With the impedance operator

$$
Z=R+X \frac{\mathrm{d}}{\mathrm{d} \omega t}
$$

the differential equations for every space-phasor network can be arranged. All in all, one gets six equations, one for every change of the conducting state. Herein, the current space-phasors are substituted according to eq. (7). That results in six complex equations, which can be separated into twelve real equations. In these, the currents are split into their steady-state (index $s$ ) and transient/homogeneous (index $h$ ) solutions, wherein the steady-state solution statements consist of an AC and a DC-current. This is shown here only for the equations derived from conducting state change $\mathrm{T}(1,2,3)$ to $\mathrm{T}(2,3)$ according to eq. (9)

$$
\begin{aligned}
& i_{d h \mathrm{~T}(1,2,3)}\left(\beta_{1}\right)-i_{d h \mathrm{~T}(2,3)}\left(\beta_{1}\right)=i_{d s A C \mathrm{~T}(2,3)}\left(\beta_{1}\right) \\
& \quad-i_{d s A C \mathrm{~T}(1,2,3)}\left(\beta_{1}\right)+I_{d s D C \mathrm{~T}(2,3)}-I_{d s D C \mathrm{~T}(1,2,3)}, \\
& -2 i_{k h \mathrm{~T}(1,2,3)}\left(\beta_{1}\right)-i_{d h \mathrm{~T}(2,3)}\left(\beta_{1}\right)=i_{d s A C \mathrm{~T}(2,3)}\left(\beta_{1}\right) \\
& \quad+2 i_{k s A C \mathrm{~T}(1,2,3)}\left(\beta_{1}\right)+i_{d s D C \mathrm{~T}(2,3)} .
\end{aligned}
$$

The steady-state and transient solution statements for all states with three conducting thyristors can be read out directly of fig. 4 with eq. (6) 


$$
\begin{aligned}
& i_{d s A C}(\omega t)=\operatorname{Re}\left\{\frac{\hat{U}_{\alpha} \mathrm{e}^{\mathrm{j}\left(\omega t+\gamma+\varphi_{a}\right)}}{R_{k}+2 / 3 R_{d}+\mathrm{j}\left(X_{k}+2 / 3 X_{d}\right)}\right\}, \\
& I_{d s D C}=-\frac{U_{d}}{3 / 2 R_{k}+R_{d}}, \\
& i_{k s A C}(\omega t)=-\operatorname{Re}\left\{\frac{\sqrt{3}}{2} \frac{\hat{U}_{\beta} \mathrm{e}^{\mathrm{j}\left(\omega t+\gamma+\varphi_{a}\right)}}{R_{k}+\mathrm{j} X_{k}}\right\}, \\
& i_{d h}(\omega t)=c_{1} \mathrm{e}^{p_{d} \omega\left(t-t_{0}\right)} \quad \text { with } p_{d}=-\frac{R_{k}+2 / 3 R_{d}}{X_{k}+2 / 3 X_{d}}, \\
& i_{k h}(\omega t)=c_{2} \mathrm{e}^{p_{k} \omega\left(t-t_{0}\right)} \quad \text { with } p_{k}=-\frac{R_{k}}{X_{k}} .
\end{aligned}
$$

For the states with two conducting thyristors analogue solution statements can be arranged. After separating the steady-state and transient solution statements as in eq. (11) and (12) the problem can be formed as matrix

$$
\mathbf{K}\left(\beta_{1}, \beta_{2}, \beta_{3}, \varphi_{1}, \varphi_{2}\right) \cdot\left[\begin{array}{c}
c_{1} \\
\vdots \\
c_{9}
\end{array}\right]=\left[\begin{array}{c}
y_{1}\left(\beta_{1}, \ldots, \varphi_{2}, \gamma\right) \\
\vdots \\
y_{12}\left(\beta_{1}, \ldots, \varphi_{2}, \gamma\right)
\end{array}\right] .
$$

Herein the left side contains the transient solutions, wherein the angles of conducting state changes $\beta_{1}$ to $\varphi_{2}$ appear in the coefficient matrix $\mathbf{K}$ as exponents of E-functions. The right side contains the steady state solutions, that additionally depend on the phase angle $\gamma$. These steady state solutions can be separated into AC and DC-parts which leads to the following description of eq. (18)

$$
\mathbf{K} \cdot \mathbf{c}=\underline{\mathbf{Y}}_{A C} \cdot\left[\begin{array}{c}
\mathrm{e}^{\mathrm{j} \gamma} \\
\mathrm{e}^{-\mathrm{j} \gamma}
\end{array}\right]+\mathbf{Y}_{D C} \cdot U_{d} .
$$

This is solved by matrix multiplication

$$
\begin{gathered}
\mathbf{c}=\left[\mathbf{K}^{T} \mathbf{K}\right]^{-1} \mathbf{K}^{T} \underline{\mathbf{Y}}_{A C}\left[\begin{array}{c}
\mathrm{e}^{\mathrm{j} \gamma} \\
\mathrm{e}^{-\mathrm{j} \gamma}
\end{array}\right]+\left[\mathbf{K}^{T} \mathbf{K}\right]^{-1} \mathbf{K}^{T} \mathbf{Y}_{D C} U_{d}, \\
{\left[\underline{\mathbf{Y}}_{A C}^{T} \underline{\mathbf{Y}}_{A C}\right]^{-1} \underline{\mathbf{Y}}_{A C}^{T} \mathbf{K} \mathbf{c}=\left[\begin{array}{c}
\mathrm{e}^{\mathrm{j} \gamma} \\
\mathrm{e}^{\mathrm{j} \gamma}
\end{array}\right]+\left[\underline{\mathbf{Y}}_{A C}^{T} \underline{\mathbf{Y}}_{A C}\right]^{-1} \underline{\mathbf{Y}}_{A C}^{T} \mathbf{Y}_{D C} U_{d} .}
\end{gathered}
$$

After inserting eq. (20) in eq. (21) and rearranging one gets

$$
\left[\begin{array}{ll}
\underline{a}_{1} & \underline{a}_{2} \\
\underline{a}_{2}^{*} & \underline{a}_{1}^{*}
\end{array}\right]\left[\begin{array}{c}
\mathrm{e}^{\mathrm{j} \gamma} \\
\mathrm{e}^{-\mathrm{j} \gamma}
\end{array}\right]=\left[\begin{array}{c}
\underline{b} \\
\underline{b}^{*}
\end{array}\right] U_{d} .
$$

Because of the steady-state AC solution statements in eq. (13) and (15), this is a conjugate-complex system of equations, which results in a relation between the DC-voltage and the phase angle $\gamma$

$$
2 \operatorname{Re}\left\{\frac{\underline{a}_{1}+\underline{a}_{2}^{*}}{\underline{b}^{*} \underline{b}^{*}} \mathrm{e}^{\mathrm{j} \gamma}\right\}=U_{d} .
$$

Herein the array elements $\underline{a}_{1}, \underline{a}_{2}$ and $\underline{b}$ depend on the angles of conducting state changes $\beta_{1}$ to $\varphi_{2}$. After pre-electing the angles $\varphi_{1}$ and $\varphi_{2}$, the problem can be solved by presuming three commutation stop-angles $\beta_{1}$ to $\beta_{3}$ and calculating the phase angle $\gamma$ with eq. (23). When the commutation stop-angles fit together, the twelve equations of eq. (18) are also satisfied. In the other case $\beta_{2}$ and $\beta_{3}$ have to be varied. This is done by computer favourably, whereas the commutation stop-angles of the idealized system can be used as an indication. For every matching triple $\beta_{1}$ to $\beta_{3}$, the time characteristics of the DC-current and the commutation current are calculable. From these, the time characteristics of the RST-values are obtained, which will now be illustrated by means of an example.

\section{Calculation of an example}

Considered is a current converter for a $750 \mathrm{~V}$ DC railroad system. The system is supplied by a $10 \mathrm{kV} / 690 \mathrm{~V}$ transformer with a rated power of $1600 \mathrm{kVA}$. Its short-circuit voltage and short-circuit power losses are

$$
\begin{aligned}
& u_{k}=6 \%, \\
& P_{v k}=14,96 \mathrm{~kW} .
\end{aligned}
$$

With this, the transformer is modelled with its short-circuit impedance. An unbalance is introduced by line $R$

$$
\begin{aligned}
& \hat{U}_{p R}=0,95 \cdot \frac{\sqrt{2}}{\sqrt{3}} \cdot 690 \mathrm{~V}, \varphi_{p R}=-5^{\circ}, \\
& \hat{U}_{p S}=\frac{\sqrt{2}}{\sqrt{3}} \cdot 690 \mathrm{~V}, \varphi_{p S}=0^{\circ}, \\
& \hat{U}_{p T}=\frac{\sqrt{2}}{\sqrt{3}} \cdot 690 \mathrm{~V}, \varphi_{p T}=0^{\circ},
\end{aligned}
$$

which leads to the following positive and negative sequences of the mains voltage space-phasor

$$
\hat{\hat{U}}_{+1}=(553,3-\mathrm{j} 15,5) \mathrm{V} \text { and } \underline{\hat{U}}_{-1}=(-10,1+\mathrm{j} 15,5) \mathrm{V}
$$

The according voltage space-phasor is shown in fig. 5 .

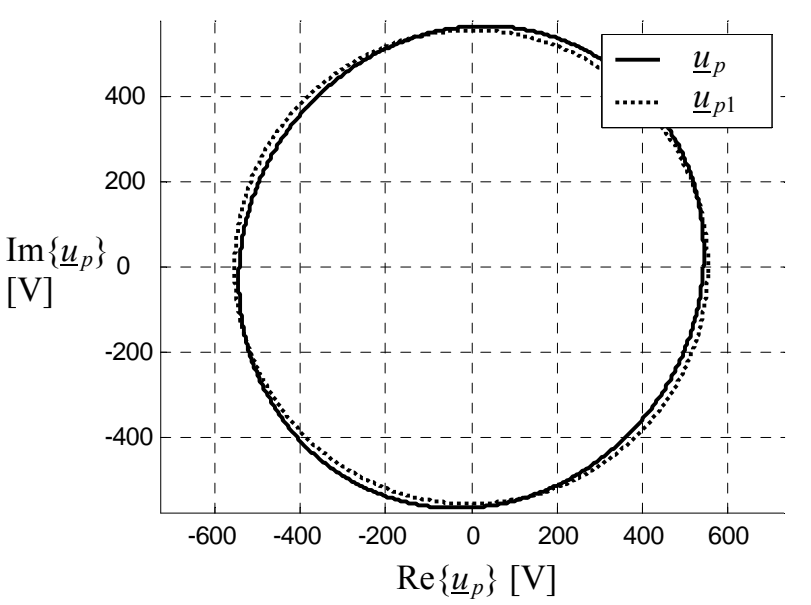

Fig. 5: Voltage space-phasor and fundamental component

On the DC-side a power of $900 \mathrm{~kW}$ is desired, so the arithmetic average DC-current has to be

$$
i_{D C, a}=1,2 \mathrm{kA} .
$$


With these parameters, the drafted approach can be executed. For every pair of $\varphi_{1}$ and $\varphi_{2}$, all currents and voltages of the system are calculable, which is done here for a range of $\varphi_{1} \in\left[50^{\circ} ; 60^{\circ}\right]$ and $\varphi_{2} \in\left[110^{\circ} ; 120^{\circ}\right]$. Knowing all currents and voltages all other parameters of interest can be calculated.

\section{A. Optimization of the AC-line currents}

For an optimization of the asymmetrical operation with respect to the AC-line currents, fig. 6 shows the THD of the AC-line currents space-phasor within the range of $\varphi_{1}$ and $\varphi_{2}$ mentioned above. The THD of the AC-line currents is minimal for $\varphi_{1}=54,2^{\circ}$ and $\varphi_{2}=117,4^{\circ}$. With these firing angles eq. (23) leads to a phase angle $\gamma=94,7^{\circ}$.

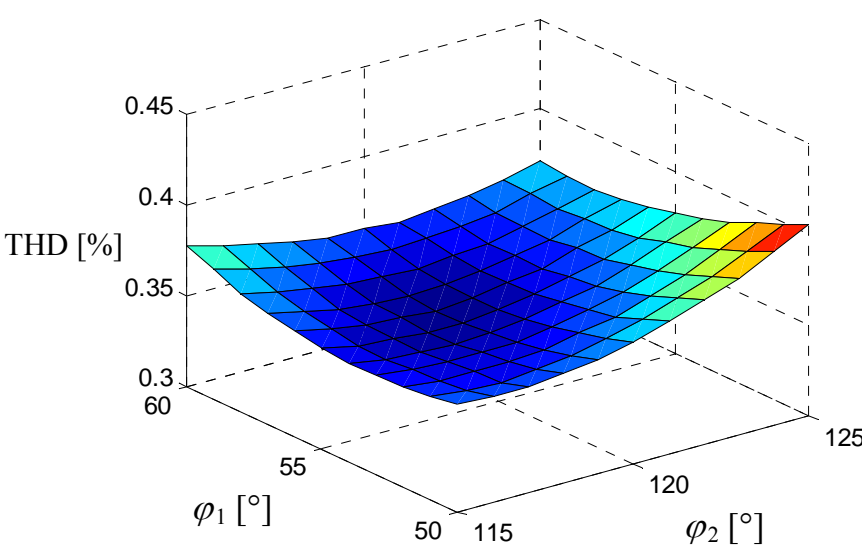

Fig. 6: THD of the AC-line currents space-phasor

In table I, some optimization results together with the results derived from a classical firing method, voltage zero crossing (VZC), are assembled. Herein $\underline{i}_{r m s}, i_{R S T, r m s}$ and $i_{d, r m s}$ are the rms-values of the current space-phasor, the AC-line currents and the DC-current. $\hat{I}_{100 \mathrm{~Hz}}$ is the amplitude of the DC-current's $100 \mathrm{~Hz}$ component.

Table I: Parameters of operation for different firing strategies

\begin{tabular}{|l|l|l|l|}
\hline & VZC & $\begin{array}{l}\text { optimized } \\
\text { THD AC }\end{array}$ & $\begin{array}{l}\text { minimized } \\
\text { DC 100Hz }\end{array}$ \\
\hline$\varphi_{1}\left[^{\circ}\right]$ & 61,7 & 54,2 & 52,6 \\
\hline$\varphi_{2}\left[^{\circ}\right]$ & 118,4 & 117,4 & 117,0 \\
\hline$\gamma\left[^{\circ}\right]$ & 92,0 & 94,7 & 95,4 \\
\hline THD AC [\%] & 37,3 & 34,8 & 35,1 \\
\hline$\underline{i}_{r m s}[\mathrm{~A}]$ & 1424,4 & 1412,2 & 1412,7 \\
\hline$i_{R, r m s}[\mathrm{~A}]$ & 934,4 & 1020,5 & 1040,2 \\
\hline$i_{S, r m s}[\mathrm{~A}]$ & 989,3 & 977,0 & 975,4 \\
\hline$i_{T, r m s}[\mathrm{~A}]$ & 1091,5 & 997,7 & 980,0 \\
\hline $\mathrm{THD} \mathrm{DC} \%]$ & 24,5 & 20,7 & 20,8 \\
\hline$i_{d, r m s}[\mathrm{~A}]$ & 1236,2 & 1225,8 & 1226,0 \\
\hline$\hat{I}_{100 \mathrm{~Hz}}[\mathrm{~A}]$ & 236,4 & 39,5 & 1,89 \\
\hline
\end{tabular}

Fig. 7 shows the space-phasors of the AC-line currents for firing angles minimizing the THD of the AC-currents and for a VZC-depending firing method. The related AC-line currents are shown in fig. 8 and 9. Fig. 10 and 11 show cut-outs of the frequency spectra. Besides a reduced distortion, optimizing the firing angles leads to more balanced AC-currents and reduced amplitudes of the non-characteristic harmonics.

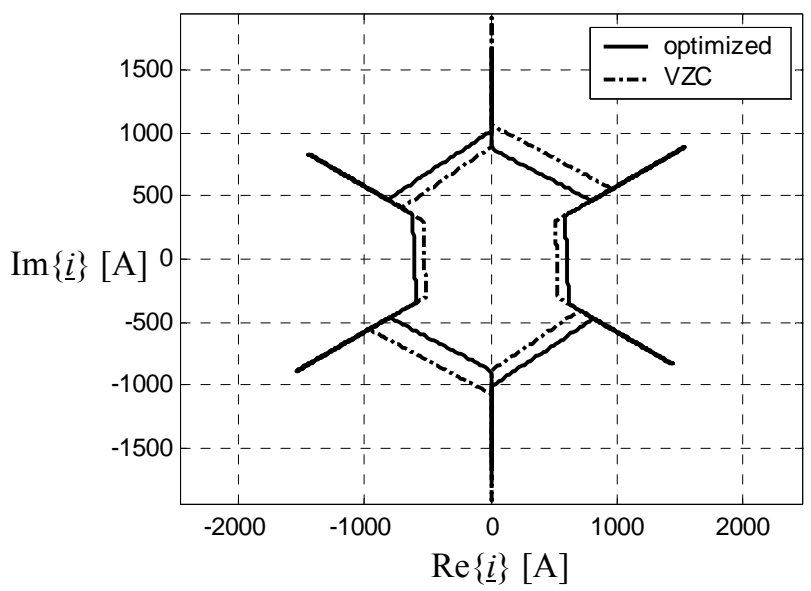

Fig. 7: AC-current space-phasors for VZC and an AC-lines THD optimized firing strategy

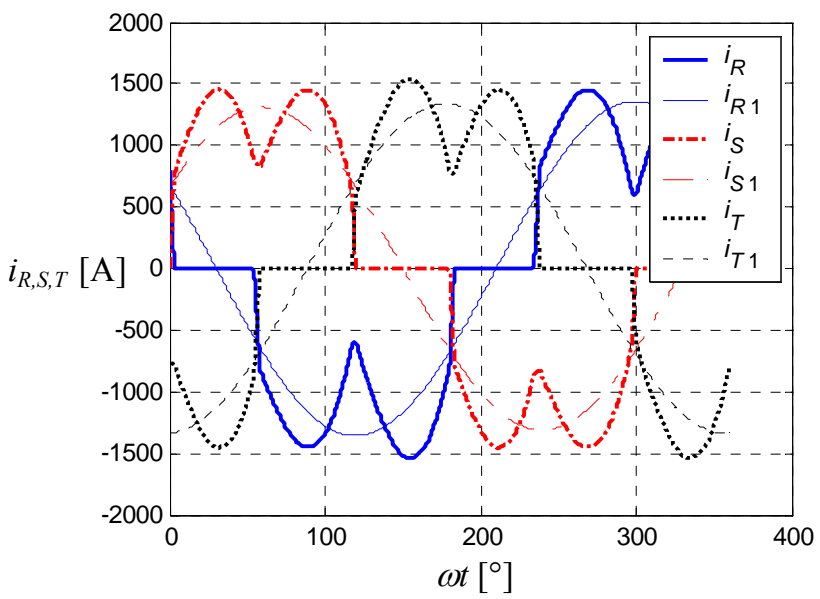

Fig. 8: AC-line currents and fundamental component for an AC-lines THD optimized firing strategy

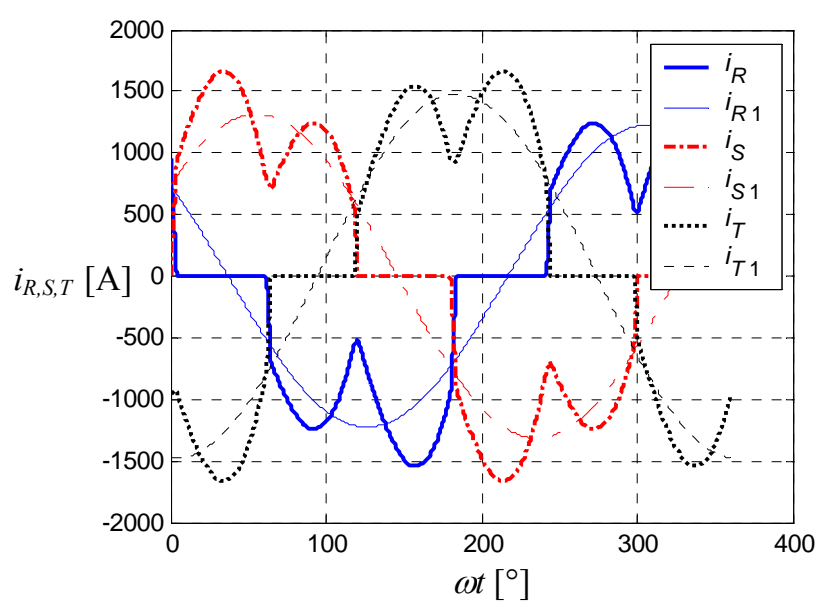

Fig. 9: AC-line currents and fundamental component for VZC firing method 


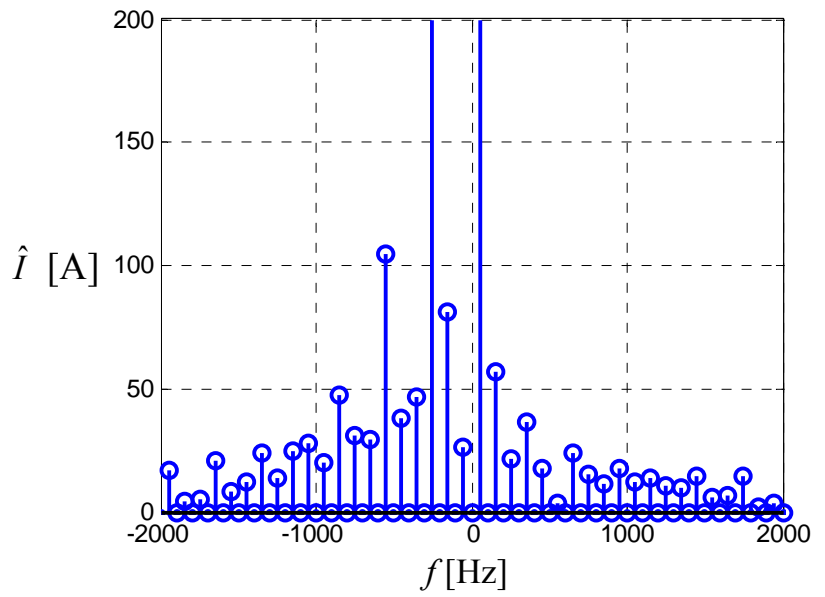

Fig. 10: Frequency spectrum of the current space phasor (opt.)

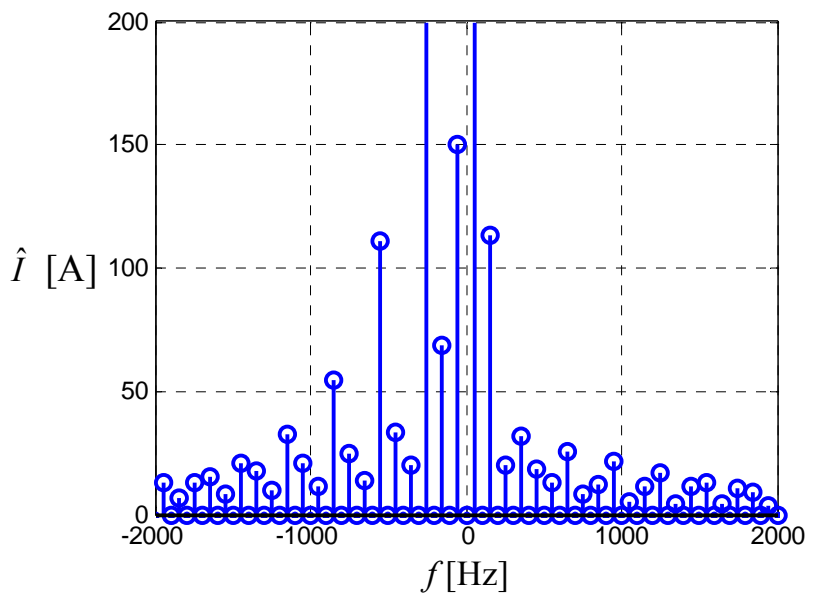

Fig. 11: Frequency spectrum of the current space phasor (VZC)

\section{B. Optimization of the DC-current}

Depending on the requirements of the application an optimization with respect to the DC-current is possible, too. This could be the minimization of its THD or the elimination of certain harmonics, for example.

In this example an elimination of the DC-current's $100 \mathrm{~Hz}$ component is desired. Therefore, fig. 12 shows the amplitude of the DC-current's $100 \mathrm{~Hz}$ component. For $\varphi_{1}=52,6^{\circ}$ and $\varphi_{2}=117,0^{\circ}$ it has is smallest amplitude of $1,89 \mathrm{~A}$, which is equal to zero within the limits of the computational accuracy.

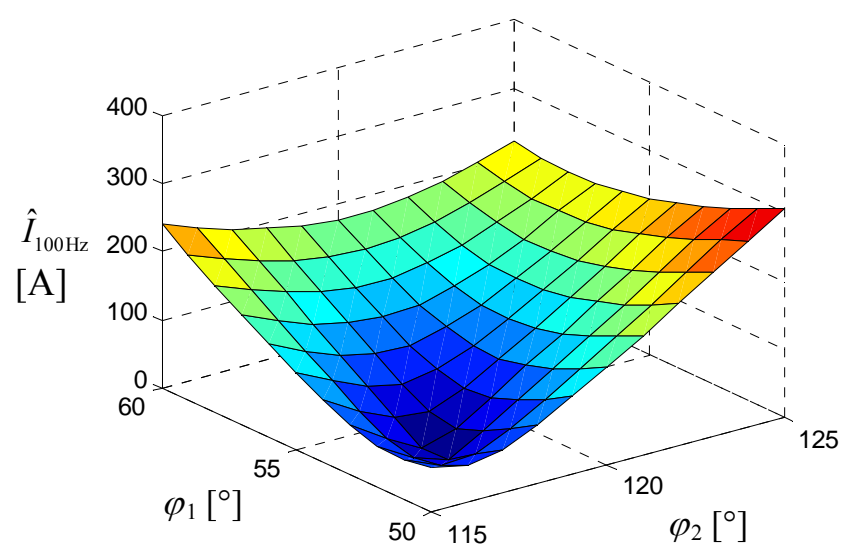

Fig. 12: Amplitude of the DC-current's $100 \mathrm{~Hz}$ component
In table I some other characteristics for this firing strategy are assembled. Fig. 13 shows the time-characteristics of the DC-current for an eliminated $100 \mathrm{~Hz}$ component. Furthermore, it shows the arithmetic average DC-current $i_{D C, a}$ plus the DC $100 \mathrm{~Hz}$ component, which is eliminated because of the optimization.

The same time-characteristics are shown in fig. 14 for the voltage-zero-crossing firing strategy.

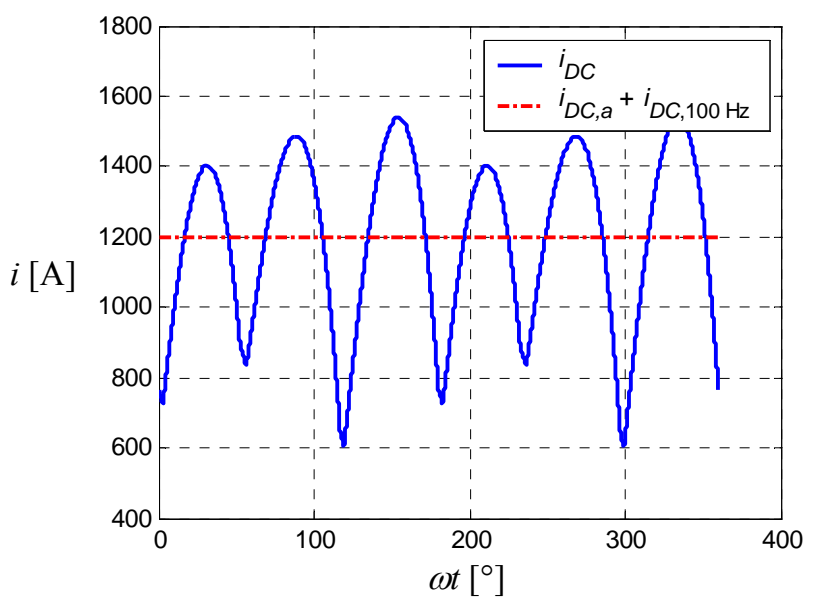

Fig. 13: DC-current for a DC-current's $100 \mathrm{~Hz}$ component minimizing firing strategies

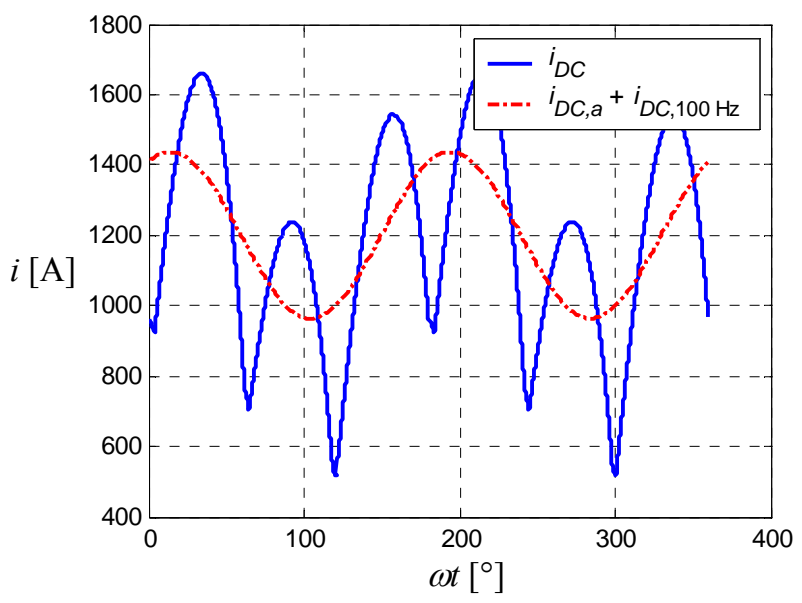

Fig. 14: DC-current for VZC firing method

At last fig. 15 and 16 show cut-outs of the spectra of the DC-current for an optimized firing strategy and the voltage-zero-crossing firing strategy.

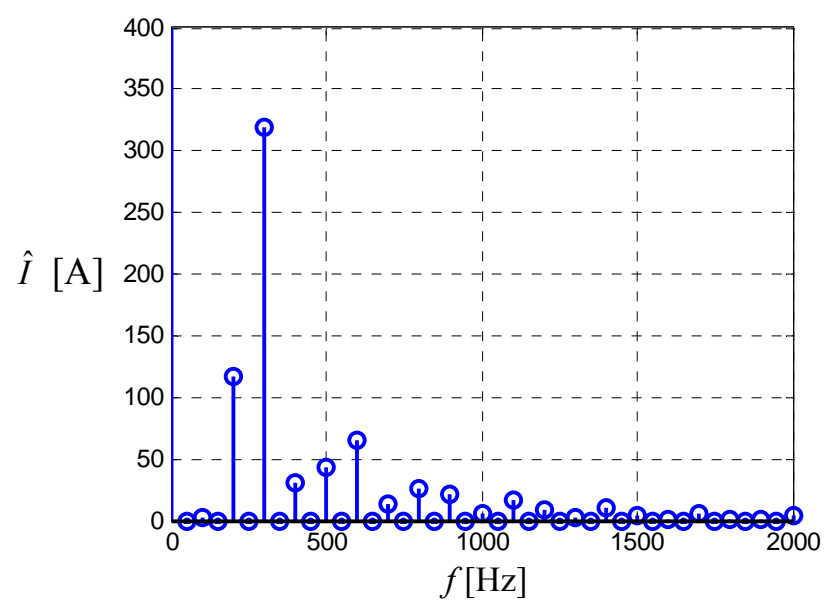

Fig. 15: Frequency spectrum of the DC-current (opt.) 


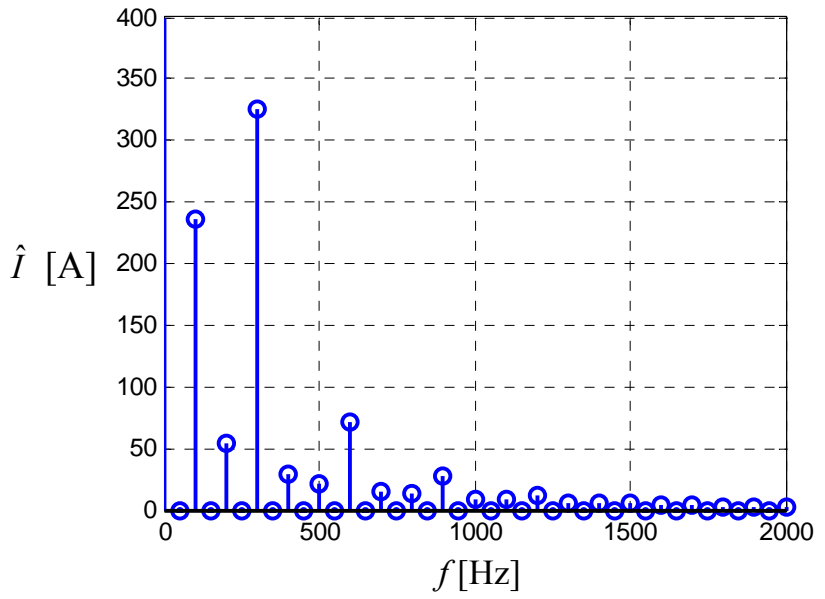

Fig. 16: Frequency spectrum of the DC-current (VZC)

\section{Interpretation of the results}

In this example, it was shown to be possible to optimize the converter's asymmetrical operation. Different optimized firing angles can be calculated depending on the aim of the optimization. Though the voltage unbalance is rather small in this example it can be pointed out, that with the shown method of calculation by optimizing the firing angles, significant improvements on the converter's behaviour can be achieved. Though this is shown in this example only for the distortion of currents and the minimization of one DC-current harmonic, the unsymmetrical operation can be optimized with respect to other criteria, too. This could be the minimization of certain harmonics of the $\mathrm{AC}$ and $\mathrm{DC}$ currents and voltages or methods for balancing the AC-lines voltage at the current converter's busbar for example.

\section{Conclusion}

In this paper, a method to calculate the operation of line-commutated current converters with unbalanced voltage sources is presented. With differential equations in the range of space-phasors, it is possible to describe and calculate arbitrary complex three-phase electrical power systems with linear network impedances.

Furthermore, with the presented method it is possible to optimize a converter's unsymmetrical operation. This optimization is shown for a certain application of a DC railroad system. For this example it is proven that an optimization is worthwhile, even if the unbalance is small.

\section{References}

[1] Cano J. M., Alonso Orcajo G., García Mayordomo J., Asensi R., Fernández Cabanas M., García Melero M.: New transfer functions for an accurate estimation of harmonic distortion in AC/DC converters working under unbalanced conditions, IEEE Trans. Ind. Applicat., Vol. 37, No. 2, pp. 642-649, 2001

[2] Macken K. J. P., De Brabandere K. M. H. A., Driesen J. J. L., Belmans R. J. M.: Evaluation of control algorithms for shunt active filters under unbalanced and nonsinusoidal conditions, IEEE Power Tech Conf., Porto, 2001
[3] Ngandui É., Olivier G., April G.-É., Guimaraes C.: DC harmonic distortion minimization of thyristor converters under unbalanced voltage supply using asymmetrical firing angle, IEEE Trans. Power Electron., Vol. 12, No. 2, pp. 332-342, 1997 [4] Yacamini R., Smith W. J.: Third-harmonic current from unbalanced AC/DC convertors, Proc. Inst. Elect. Eng., Vol. 130, Pt. C, No. 3, pp. 122-126, 1983

[5] De Haan S. W. H.: Analysis of the effect of source voltage fluctuations on the power factor in three-phase controlled rectifiers, IEEE Trans. Ind. Applicat., Vol. IA-22, No. 2, pp. 259266, 1986

[6] Sakui M., Fujita H.: Calculation of harmonic currents in a three-phase convertor with unbalanced power supply conditions, Proc. Inst. Elect. Eng., Vol. 139, Pt. B, No. 5, pp. 478484, 1992

[7] Rashid M. H., Maswood A. I.: A novel method of harmonic assessment generated by three-phase AC-DC converters under unbalanced supply conditions, IEEE Trans. Ind. Applicat., Vol. 24, No. 4, pp. 590-597, 1988

[8] Enjeti P. N., Ziogas P. D.: Analysis of a static power converter under unbalance: A novel approach, IEEE Trans. Ind. Electron., Vol. 37, No. 1, pp. 91-93, 1990

[9] Draessler M., Jirsa J., Žáček J.: The influence of power mains unbalance on parameters of three-phase bridge rectifier with capacitive filter, 11th International Power Electronics and Motion Control Conference, Riga, 2004

[10] Christoforidis G. P., Meliopoulos A. P. S.: Effects of modeling on the accuracy of harmonic analysis, IEEE Trans. Power Delivery, Vol. 5, No. 3, pp. 1598-1606, 1990

[11] Maswood A. I., Rashid M. H.: Unbalance supply and its effect on rectifier input filter kVA ratings, IEEE Applied Power Electron. Conf., pp. 333-336, Dallas, 1991

[12] Paulillo G., Abreu J. P. G.: Power converters under voltage imbalance - A novel solution, IEEE Power Tech Conf., Porto, 2001

[13] Poullain S., Courbon E., Thomas J.-L., VSC-HVDC robust control scheme in unbalanced network conditions, 10th European Conference on Power Electronics and Applications, Toulouse, 2003

[14] Jensen U. B., Enjeti P. N., Blaabjerg F.: A new space vector based control method for UPS systems powering nonlinear and unbalanced loads, IEEE Applied Power Electron. Conf., pp. 895-901, New Orleans, 2000

[15] Herold G., Weindl Ch.: State space calculation of 6-pulse current converter bridges in steady-state, Electrical Engineering 80, pp. 51-64, 1997

[16] Rendusara D., von Jouanne A., Enjeti P., Paice D. A. Design considerations for six pulse and twelve pulse diode rectifier systems operating under voltage unbalance and pre-existing voltage distortion with some corrective measures, IEEE Ind. Applicat. Conf., pp. 2549-2556, 1995

[17] Herold G., Ebner G., Unsymmetrical operation of a DIPFC to reduce network interactions, IEEE Power Tech Conf., St. Petersburg, 2005

[18] Hu J., He Y.: Modeling and control of grid-connected voltage-sourced converters under generalized unbalanced operation conditions, IEEE Trans. Energy Conv., Volume 23, Issue 3, pp. 903-913, 2008

[19] Hwang J. G., Lehn P. W.: Control of AC-DC converters under unbalanced operating conditions using the DC space vector control concept, Power Electronics Specialists Conference PESC, pp. 830-836, 2008

[20] Hyosung K., Blaabjerg F., Bak-Jensen B., Choi J.: Novel instantaneous power compensation theory in three-phase systems, 8th European Conference on Power Electronics and Applications, Graz, 2003 